\title{
Trends in Prostate Cancer Prevalence and Radical Prostatectomy Rate according to Age Structural Changes in South Korea between 2005 and 2015
}

\author{
Hyun Young Lee ${ }^{1}$, Suyeon Park ${ }^{2}$, Seung Whan Doo $^{1}$, Won Jae Yang ${ }^{1}$, Yun Seob Song ${ }^{1}$, and Jae Heon Kim ${ }^{1}$ \\ ${ }^{1}$ Department of Urology, Soonchunhyang University Seoul Hospital, Soonchunhyang University Medical College, Seoul; \\ ${ }^{2}$ Department of Biostatistics, Soonchunhyang University Seoul Hospital, Seoul, Korea.
}

Purpose: Radical prostatectomy (RP) is one of main treatments for prostate cancer (Pca). The prevalence of Pca has been decreasing in recent reports. However, no study has reported trends in Pca prevalence or RP rate according to age structural changes. The objective of this study was to investigate trends in Pca prevalence and frequency of RP according to age structural change. Materials and Methods: We evaluated trends in Pca prevalence and RP rate using National Health Insurance Data from 2005 to 2015. Relationships for Pca prevalence and RP rate with age structural change were also determined. Primary outcomes included trends in Pca prevalence and RP rates according to age groups, comparing those before and after 2011.

Results: Pca prevalence tended to increase before 2011 and decreased after 2011 in persons in the 60-years age group. RP rate increased pattern before 2011 and decreased after 2011 in age groups of 50s, 60s, and over 70s. Pca prevalence and age structural change showed a significantly positive relationship in all age groups, except for the age group under 40 years. RP rate and age structural change also showed a significantly positive relationship in all age groups.

Conclusion: Age structural change can affect the decreasing trend in Pca prevalence and RP rate in South Korea. Future studies are needed to validate this result.

Key Words: Prostate cancer, prostatectomy, prevalence

\section{INTRODUCTION}

Prostate cancer (Pca) is one of the most frequent cancers in men worldwide. ${ }^{1}$ The incidence of Pca is consistently increasing with aging societies. Pca has been the most frequent urological cancer since 2004. The number of patients who are di-

Received: November 22, 2018 Revised: January 22, 2019

Accepted: January 24, 2019

Corresponding author: Jae Heon Kim, MD, PhD, Department of Urology, Soonchunhyang University Seoul Hospital, Soonchunhyang University College of Medicine, 59 Daesagwan-ro, Yongsan-gu, Seoul 04401, Korea.

Tel: 82-2-709-9375, Fax: 82-2-795-3687, E-mail: piacekjh@schmc.ac.kr

-The authors have no potential conflicts of interest to disclose.

(C) Copyright: Yonsei University College of Medicine 2019

This is an Open Access article distributed under the terms of the Creative Commons Attribution Non-Commercial License (https://creativecommons.org/licenses/ by-nc/4.0) which permits unrestricted non-commercial use, distribution, and reproduction in any medium, provided the original work is properly cited. agnosed with Pca has remained greater than the sum of patients who are diagnosed with bladder and renal cancers since 2008 . $^{2}$ Moreover, the mortality of Pca has sharply increased about 12 times, as of 2002, compared to 1983 . Pca is the most rapidly increasing cancer among all cancers in South Korea. ${ }^{3,4}$

The social burden of Pca, including medical cost, has increased consistently. This is associated with the increasing prevalence of Pca due to not only the increased incidence of Pca, but also due to an increased survival rate among Pca patients. ${ }^{5}$ In the United States, the cost burden of Pca treatment was estimated to be 10 billion dollars in 2006. In Japan, it was 174.5 billion yen in 2002 . The cost is expected to be much higher in 2020 . $^{6,7}$

Compared to other treatments, radical prostatectomy (RP) is chosen more for younger and less morbid patients who are less likely to have peri-operative or post-operative complications than for older patients. ${ }^{8}$ However, about $80 \%$ of Pca patients 
are over 65 years of age. Age at diagnosis of Pca has increased consistently over the last 10 years. ${ }^{9,10}$ This phenomenon could be explained by age structural change and decreased Pca screening test. Recent evidence suggests that patients are undergoing $\mathrm{RP}$ at a higher age than before. However, RP rate are decreasing compared to rates for other treatments, including watchful waiting, active surveillance, radiation therapy, and hormone therapy. ${ }^{11,12}$ This phenomenon could be more prominent in South Korea, considering that this country has the highest speed of age structural change and a relatively high proportion of RP, compared to the United States, which has other treatment options. Thus, determining the trend of Pca prevalence according to age structural change is important for estimating the future disease burden of Pca. ${ }^{12,13}$

To date, there are no standard guidelines for screening for Pca, including performance of prostate-specific antigen (PSA), in South Korea. Regarding the performance of prostate biopsy, indicated criteria include more than 5 years of remnant life expectancy and patients with symptoms. ${ }^{14}$

South Korea is now facing the issue of an aging society. It has the lowest fertility rate among all Organization for Economic Cooperation and Development (OECD) countries. The proportion of South Korea's population over 65 years was more than $10 \%$ in 2008 and $15 \%$ in 2015 . It is expected to increase to about $30 \%$ by $2030 .^{15,16}$

Because healthcare budgets are limited, it is important to allocate the budget in consideration of the balanced benefit of healthcare. If there is a decreasing trend for RP in Pca and if the possible phenomenon could be explained by aging changes, medical and healthcare funding can be distributed appropriately, and other treatments, such as watchful waiting, active surveillance, radiation therapy, and hormone therapy, should be considered.

Our previous study revealed that age structural changes can affect the performance of urologic diagnostic tools. ${ }^{17}$ Considering an increasing socioeconomic burden due to an increased prevalence of Pca and the lack of studies on age structural changes in Pca patients, the objective of this study was to investigate trends in Pca prevalence and frequency of surgical treatment according to age structural change using National Health Insurance Data covering $99 \%$ of all South Korean men.

\section{MATERIALS AND METHODS}

\section{Data collection}

Annual reports of cancer statistics from National Health Insurance Service (NHIS) of South Korea between 2005 and 2015 were used. The National Health Insurance (NHI) program in South Korea was started in 1970s; this program came to offer universal health care in 1989 . The NHIS covers $99 \%$ of all South Koreans and provides information about the number of patients with each type of cancer registered in NHI, including age, gender, diagnosis, medical procedures, and so on. ${ }^{17} \mathrm{Pca}$ (C61) was coded according to the Korean standard classification of disease and cause of death, 6th edition (KCD-6). We collected the number of males in South Korea from 2005 to 2015 from the Korean Statistical Information Service (KOSIS). The KOSIS collects economic, social, and medical statistics for South Korea. Among patients who had a code of C61 from 2005 to 2015 , we selected patients who had received primary treatment for Pca, such as surgical treatment. This work was approved by the Institutional Review Board of Soonchunhyang University Seoul Hospital (SCHUH 2018-12-020).

Surgical treatment included radical prostatectomy, such as retropubic $\mathrm{RP}$, perineal $\mathrm{RP}$, laparoscopic $\mathrm{RP}$, and robot-assisted laparoscopic prostatectomy (RALP). Reimbursement codes of RP in NHIS were R3950, R3960, and RZ512. RALP had no code because it was not reimbursed by NHIS. An alternative defining method was used to detect RALP using codes of general anesthesia (L1211) and postoperative pathologic examination (C5500, C5501, C5502, C5503, C5504, C5505, C5506, C5507, C5508, C5509, C5911, C5912, C5913, C5914, C5915, C5916, C5917, C5918, C5919). ${ }^{18}$

\section{Measurement outcomes}

The primary outcomes of this study were the following two relationships: 1) between annual Pca prevalence and age structural change, and 2) between annual trend in operation rate and age structural change. To investigate these two outcomes, cumulative age-standardized prevalence rates per year according to age groups, cumulative age-standardized operation rates per year according to age groups, age-standardized operation rates/patients per year according to age groups, correlation between Pca patient rates per year and percentage of population, correlation between operation rates per year and percentage of population, and correlation between operations/ patients rates per year and percentage of population were measured. We subdivided age into the following groups: less than 40 years old, 40 s, 50 s, 60 s, and over 70 years old. We described all outcomes as rates standardized as per 100000 males using real general population of the relevant year.

\section{Data analysis}

The total number of males per year was calculated for each age group in South Korea using data of National Statistical Office. The total number of Pca patients and total number of operations per year according to age groups were calculated based on diagnosis codes. Cumulative patient and operation rates according to year were analyzed. Cumulative age-standardized patients and operations according to year and age groups were also analyzed. For analysis, generalized linear models were used. Results are displayed as estimates with standard errors and were plotted as a line graph. Analysis was performed for cumulative age-standardized patient rates per 100000 people, operation rates per 100000 people, and opera- 
tion/patient rates according to year and age groups. Piecewise linear regression model was used to compare trends before and after 2011. Analysis was performed for correlation coefficients between patient rates and percentage of population, between operation rates and percentage of population, and between operation rates/patient rates and percentage of population per year. Statistically significant differences were considered when $p$ was less than 0.05 . All data were analyzed using R software (v3.1.2; R Foundation, Vienna, Austria).

\section{RESULTS}

\section{Annual trends in prevalence, operation rate, and operation rate/patient rates}

Table 1 shows the trend test results for Pca patients, operations, and operations/patients of all Pca patients after age adjustment according to age groups. Overall trends in patients and operations showed increases over the study period $(\beta=$ 2.553, $p=0.000$; and $\beta=1.285, p=0.000$, respectively). However, the overall trend in operations/patients nearly did not change $(\beta=0.01, p=0.037)$. Remarkably, trends in patients in the age groups of 60 and over 70 years showed increasing patterns in the study period $(\beta=5.904, p=0.002$; and $\beta=11.795, p=0.000$, respectively). Trends in operations in the 60 s and over 70 s age groups also showed increasing patterns $(\beta=4.722, p=0.001$; and $\beta=6.37, p=0.000$, respectively). However, trends in operations/patients in age groups of 60 s and over 70 s showed statistically insignificant patterns $(\beta=-0.008, p=0.543$; and $\beta=-0.005$, $p=0.703$, respectively). Table 2 shows piecewise linear regression results of Pca patients in the overall population according to age grouping and trend test results before and after 2011 . Trends in Pca patients followed an increasing pattern before 2011 and a decreasing pattern after 2011 in the 60s age group $(\beta=13.789, p=0.000$ before 2011 ; and $\beta=-5.929, p=0.000$ after 2011). Table 3 shows the results of piecewise linear regression of operations in the overall population according to age groups. Trends in operations also had an increasing pattern before 2011 and a decreasing pattern after 2011 in the age groups of 50s, 60s, and over 70s $(\beta=1.772, p=0.000$ before 2011 and $\beta=$ -0.728, $p=0.040$ after 2011 in 50s; $\beta=11.65, p=0.000$ before 2011 and $\beta=-5.907, p=0.000$ after 2011 in $60 \mathrm{~s} ; \beta=13.022, p=0.000$ before 2011 and $\beta=-3.667, p=0.022$ after 2011 in over 70s). Table 4 shows the results of piecewise linear regression of operations/patients in the overall population according to age groups. Trends in operations/patients followed an increasing pattern before 2011 and a decreasing pattern after 2011 in age groups of $50 \mathrm{~s}, 60 \mathrm{~s}$, and over $70 \mathrm{~s}(\beta=0.025, p=0.007$ before 2011 and $\beta=-0.029, p=0.010$ after 2011 in 50 s; $\beta=0.031, p=0.000$ before 2011 and $\beta=-0.025, p=0.002$ after 2011 in 60s; $\beta=0.031, p=$ 0.000 before 2011 and $\beta=-0.018, p=0.000$ after 2011 in over 70s). Fig. 1 shows patient rates and operation rates per 100000 people per year. Both showed increasing patterns during the study period. However, the increasing speed decreased after 2011. Fig. 2 shows cumulative age-standardized prevalence rates and operation rates per year according to age groups. The rates exhibited a plateau pattern that peaked in 2011, showing a decreasing pattern in age groups of 60 s and over 70 s. Fig. 3 shows age-standardized operation rates/patients per year according to age groups. These rates also had a plateau pattern. They increased until 2009 (46\%), with a similar portion until 2013, and decreased (41\%) in 2015.

\section{Relationships between trends in Pca prevalence, operation rates, or operation rates/prevalence and age structural changes per year}

Fig. 4 shows the relationships between patient rates and percentage of population per year according to age groups. The red line represents trends in patient rates per year, while the black line represents trends in the percentage of population. Patient rate and percentage of population of each age group had a positive relationship ( $\mathrm{r}=0.79, p=0.004$ in $40 \mathrm{~s}$; $\mathrm{r}=0.915, p=$ 0.000 in $50 \mathrm{~s} ; \mathrm{r}=0.633, p=0.037$ in $60 \mathrm{~s} ; \mathrm{r}=0.845, p=0.001$ in over $70 \mathrm{~s})$ except for the age group of under 40 years $(\mathrm{r}=0.044, p=$ 0.897). Fig. 5 shows the relationship between operation rate and percentage of population per year according to age groups. The red line represents the trend in operation rate per year, while the black line represents the trend in percentage of population. The operation rate of Pca and percentage of population of each age group also had a positive relationship $(\mathrm{r}=$ 0.935, $p=0.000$ in 40s; $r=0.837, p=0.001$ in 50s; $r=0.582, p=0.050$ in 60s; and $r=0.825, p=0.002$ in over 70s) except for the age group of under $40(\mathrm{r}=-0.142, p=0.677)$. Fig. 6 shows the relationship between operation rates/patients and the percentage of population per year according to age groups. The red line represents the trend of operation rates/patients per year, while the black line represents the trend of percentage of population. Operation rates/patients and percentage of population per year had no significant relationship $(\mathrm{r}=-0.316, p=0.343$ in under 40 years; $\mathrm{r}=0.529, p=0.094$ in $40 \mathrm{~s} ; \mathrm{r}=0.339, p=0.307$ in $50 \mathrm{~s} ; \mathrm{r}=0.489, p=0.125$ in $60 \mathrm{~s}$ ), except for the age group of over 70 years $(\mathrm{r}=0.788, p=0.004)$.

\section{DISCUSSION}

This is the first study to investigate trends in the prevalence of Pca and operation rates according to age structural change. Investigating such trends is an important issue because South Korea has become an aged society. This study provides useful evidence with which to predict future medical costs of Pca treatment. We had two main hypotheses: 1) Pca prevalence and surgical treatment rate would be affected by age structural changes; 2) considering rapid decreases in younger individuals, surgical treatment rates would decrease without showing correlations with the increasing age of the popula- 


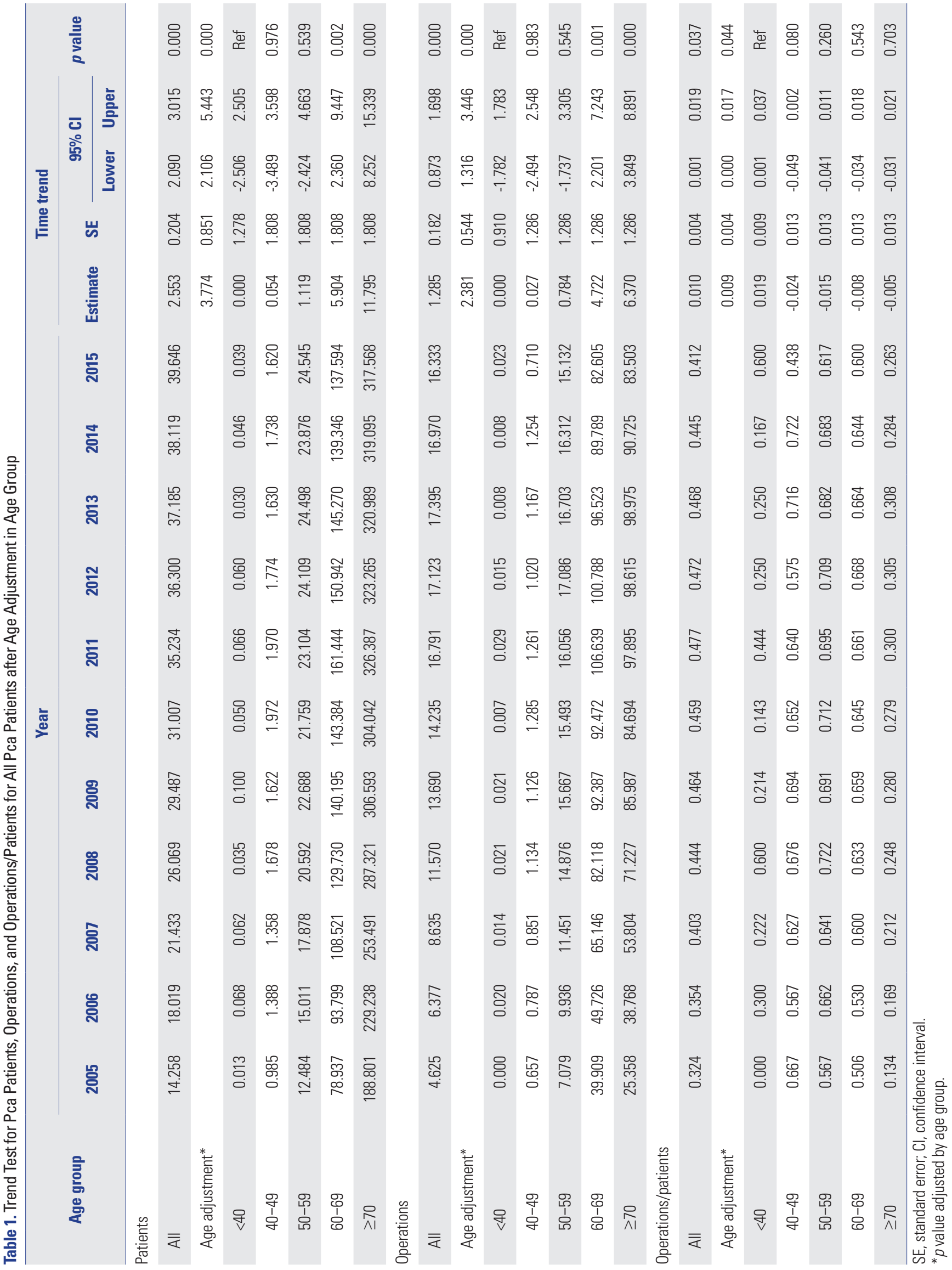


Table 2. Piecewise Linear Regression of Pca Patients in the Overall Population and Age Groups

\begin{tabular}{ccccc}
\hline & & \multicolumn{3}{c}{ Trend test } \\
\cline { 3 - 5 } & & beta & SE & p value* \\
\hline \multirow{2}{*}{ Overall } & $<2011$ & 8.017 & 12.488 & 0.524 \\
& $\geq 2011$ & -1.585 & 16.520 & 0.924 \\
Age group & & & & \\
\multirow{2}{*}{$<40$} & $<2011$ & 0.007 & 0.006 & 0.239 \\
& $\geq 2011$ & -0.007 & 0.007 & 0.366 \\
\multirow{2}{*}{$40-49$} & $<2011$ & 0.170 & 0.027 & 0.000 \\
& $\geq 2011$ & -0.073 & 0.035 & 0.037 \\
\multirow{2}{*}{$50-59$} & $<2011$ & 2.060 & 0.249 & 0.000 \\
& $\geq 2011$ & 0.265 & 0.329 & 0.421 \\
$60-69$ & $<2011$ & 13.789 & 1.072 & 0.000 \\
& $\geq 2011$ & -5.929 & 1.419 & 0.000 \\
270 & $<2011$ & 24.060 & 2.508 & 0.000 \\
& $\geq 2011$ & -2.181 & 3.318 & 0.511 \\
\hline
\end{tabular}

SE, standard error.

${ }^{*} p$ value by piecewise linear regression and adjusted by age group.

Table 3. Piecewise Linear Regression of Operations in the Overall Population and Age Groups

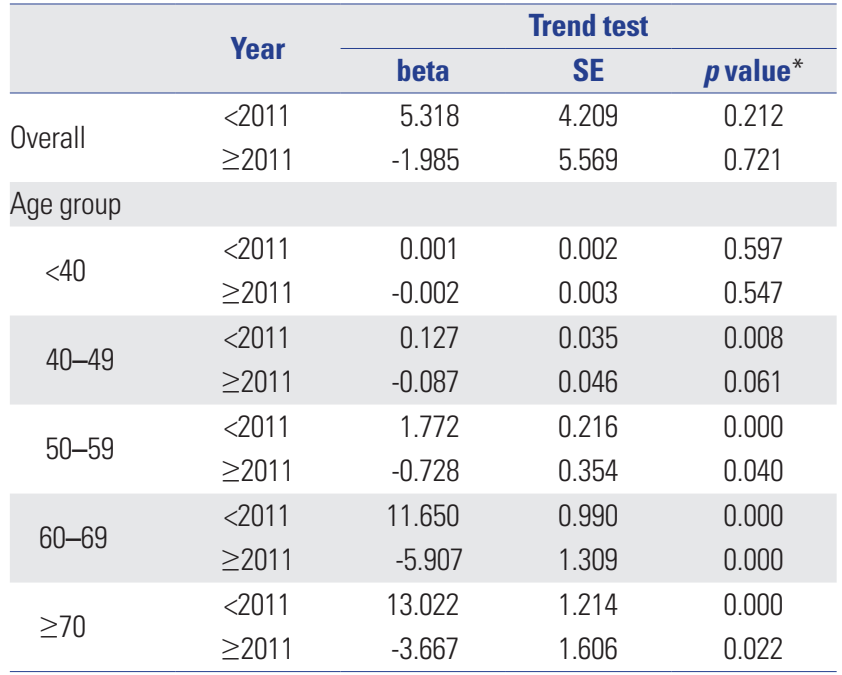

SE, standard error.

${ }^{*} p$ value by piecewise linear regression and adjusted by age group.

tion. Hence, we used prevalence of Pca and age-specific operation rates of Pca. Prevalence was used as an indicator of real demand for Pca treatment, because it reflects the changing status of treatment patterns. Thus, it would be affected by recent age structural changes.

Due to the absence of standard guidelines for screening of Pca, the performance of PSA is generally done during a general health checkup or during an initial evaluation of benign prostatic hyperplasia. Considering the continuously rising phenomenon of Pca specific mortality in South Korea, the costeffectiveness of Pca screening has to be refocused again..$^{19}$

In the United States, over one-third of all patients who underwent operation treatment were patients aged over 65
Table 4. Piecewise Linear Regression of Operations/Patients in the Overall Population and Age Groups

\begin{tabular}{|c|c|c|c|c|}
\hline & Voar & & rend te & \\
\hline & Teal & beta & SE & $p$ value ${ }^{*}$ \\
\hline Overall & $<2011$ & 0.025 & 0.022 & 0.280 \\
\hline Uverall & $\geq 2011$ & -0.009 & 0.030 & 0.762 \\
\hline Age group & & & & \\
\hline ח & $<2011$ & 0.014 & 0.049 & 0.781 \\
\hline$<40$ & $\geq 2011$ & 0.046 & 0.081 & 0.568 \\
\hline $10-10$ & $<2011$ & 0.011 & 0.021 & 0.616 \\
\hline $4 u-4 y$ & $\geq 2011$ & -0.037 & 0.034 & 0.285 \\
\hline $50-59$ & $<2011$ & 0.025 & 0.007 & 0.007 \\
\hline $20-39$ & $\geq 2011$ & -0.029 & 0.011 & 0.010 \\
\hline $60-69$ & $<2011$ & 0.031 & 0.005 & 0.000 \\
\hline $00-05$ & $\geq 2011$ & -0.025 & 0.008 & 0.002 \\
\hline$>70$ & $<2011$ & 0.031 & 0.003 & 0.000 \\
\hline 210 & $\geq 2011$ & -0.018 & 0.005 & 0.000 \\
\hline
\end{tabular}

SE, standard error.

${ }^{*} p$ value by piecewise linear regression and adjusted by age group.

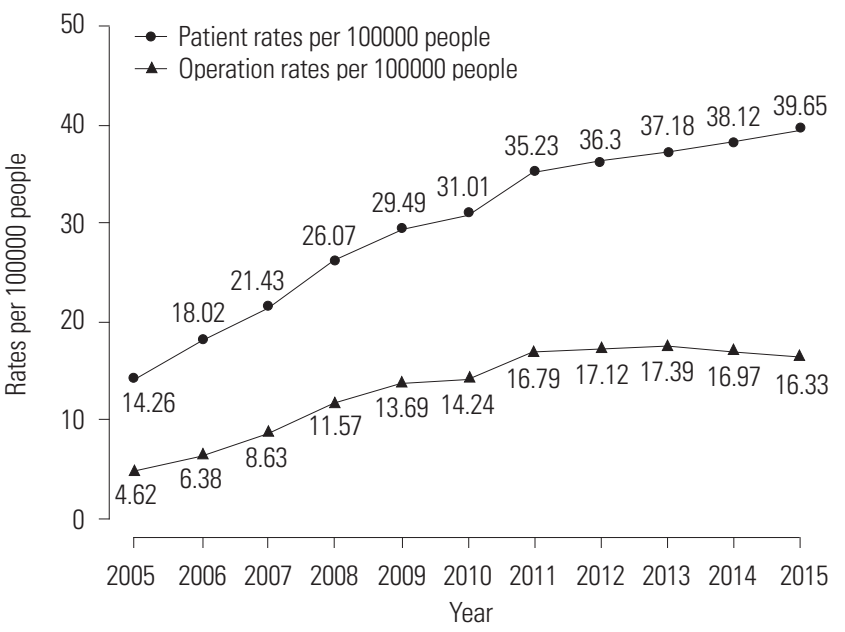

Fig. 1. Prevalence and operation rates of prostate cancer per year per 100000 people.

years. Over half of the patients who underwent RP were aged over 65 years in 2007. 20,21 According to demographic changes in an aging society, this trend will become of greater importance in future health care.

Due to age structural changes and decreased opportunities for screening tests for Pca, age at diagnosis has increased. Reportedly, patients underwent RP at a higher age than before, resulting in a decreasing portion of surgical treatments. ${ }^{11} \mathrm{Pca}$ in South Korea had shown an increasing trend until 2011. After 2011, its increasing speed slowed. Song and Jeon ${ }^{2}$ have reported that the incidence of Pca rapidly increased in the age group of 55-59 years, showing a peak increasing rate in the age group of 70-74 years from 1999 to 2010. Considering South Korea is becoming an aging society at a high rate, older age groups could have a higher prevalence rate than relatively younger age groups. In our results, the prevalence of Pca in- 

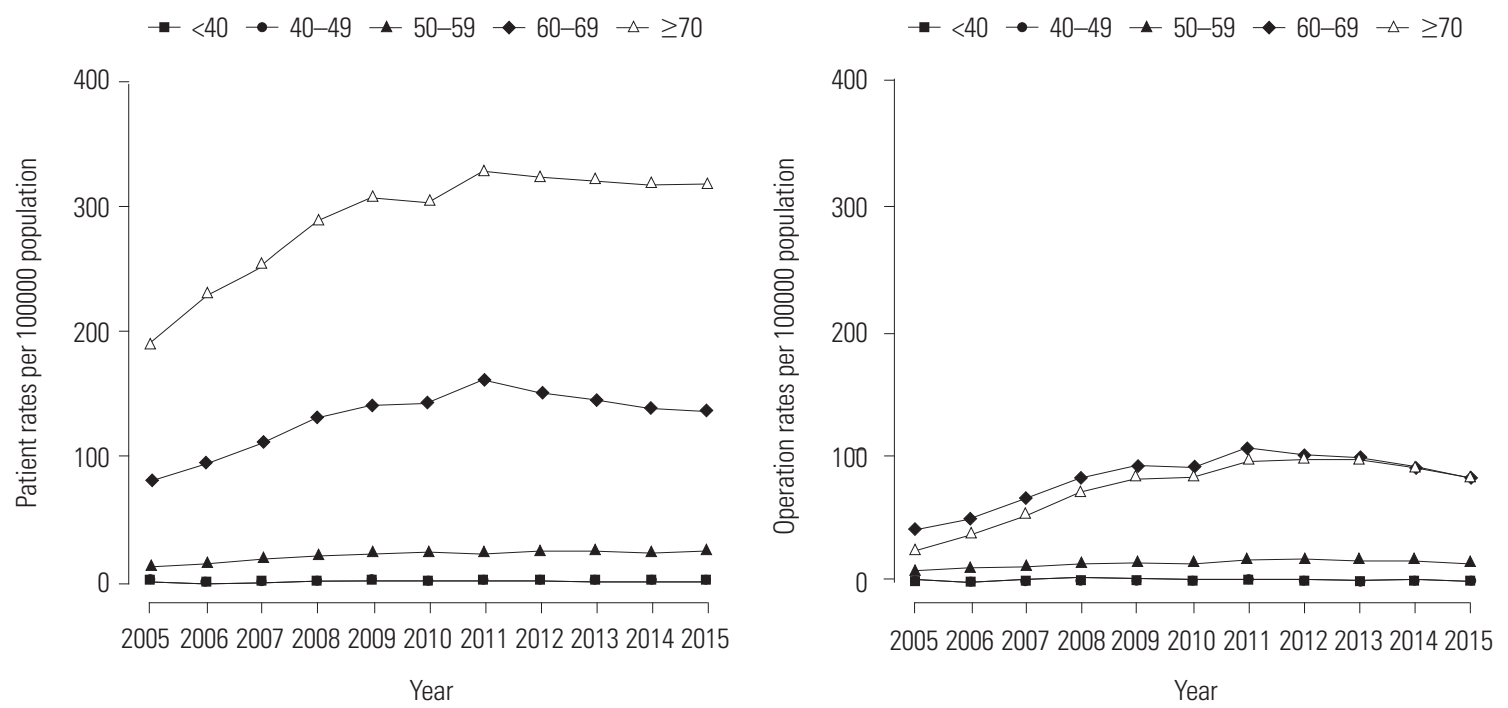

Fig. 2. Cumulative age-standardized patient rates and operation rates per year by age group.

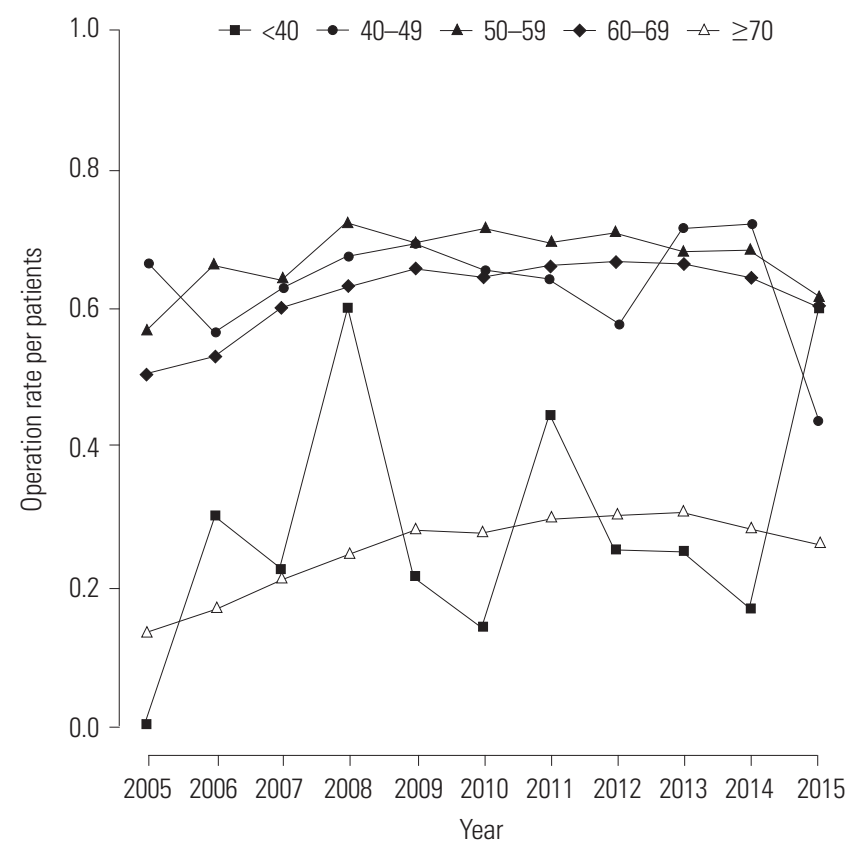

Fig. 3. Age-standardized operation rates/patients per year by age group.

creased until 2014, but decreased in 2015, while surgical treatments increased until 2013, but decreased from 2014. Unless Pca detection rates decreased, this meant that Pca patients chose other treatment options, such as watchful waiting, active surveillance, radiation therapy, and hormone therapy. Because Pca incidence was not decreased and Pca mortality was slightly increased in South Korea, the stabilization or decrease in Pca prevalence could be explained by a decrease in the utilization rate of medical services. ${ }^{22,23}$

Chen, et al. ${ }^{12}$ have studied national trends in Pca in the United States from 2004 to 2013, a study period similar to ours. Regarding operation rates, there were also about $35 \%$ of Pca patients who were treated by operation, showing a peak operation rate of $40 \%$ in $2007 .{ }^{12}$ The operation rate then began to decrease from 2013. ${ }^{12}$ Their study showed similar findings to our study in that the number of Pca patients increased with higher age at diagnosis, while the number of Pca patients who chose surgical treatment for Pca decreased with higher age at diagnosis. ${ }^{12}$ They concluded that the trend was that younger patients had more proper surgical treatment, while older patients sought non-surgical treatment, although surgical technique had improved.

The decreasing Pca prevalence might reflect several possibilities. First, the number of screening tests performed for Pca decreased. In South Korea, almost 15\% of all male South Koreans over 50 years old undergo PSA screening, compared to $75 \%$ of all males in the United States. Additionally, in 2011, the USPSTF recommended restrict routine screening test for Pca using PSA, because it might cause over-diagnosis and overtreatment. ${ }^{24}$ Many urologists might be influenced by this recommendation, especially when they treat older patients. Second, medical utilization rates decreased among older patients due to various reasons, including financial dependence on their supporters. Failure to maintain financial independence in older adults can cause a reduction in individual medical expenditures and eventually decrease medical utilization rates. ${ }^{25}$ The decreasing trend in RP could be explained by patient preference for safer and more convenient treatment strategies, including watchful waiting, active surveillance, radiation therapy, and hormone therapy over surgical therapy. ${ }^{26,27}$

Tamada, et al. ${ }^{27}$ have reported that treatment outcomes are similar between radiation therapy and surgical treatment. They compared the two using overall survival, cancer-specific survival, and biochemical failure-free survival. Cancer-specific survival was similar between the two groups, although surgical treatment was superior to radiation therapy in overall survival. Otherwise, radiation therapy was superior to surgical treatment in biochemical failure-free survival. Post-treatment 

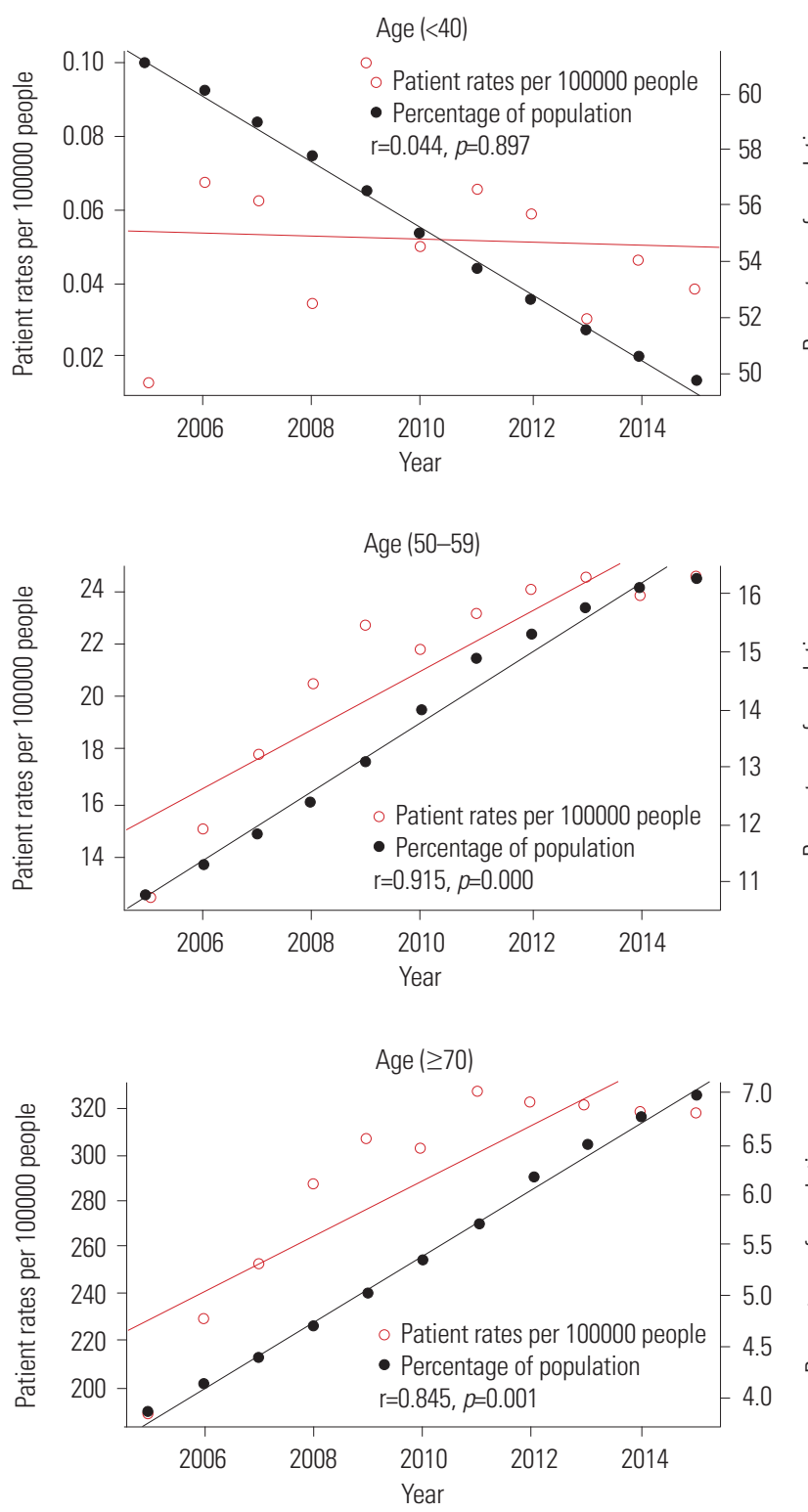
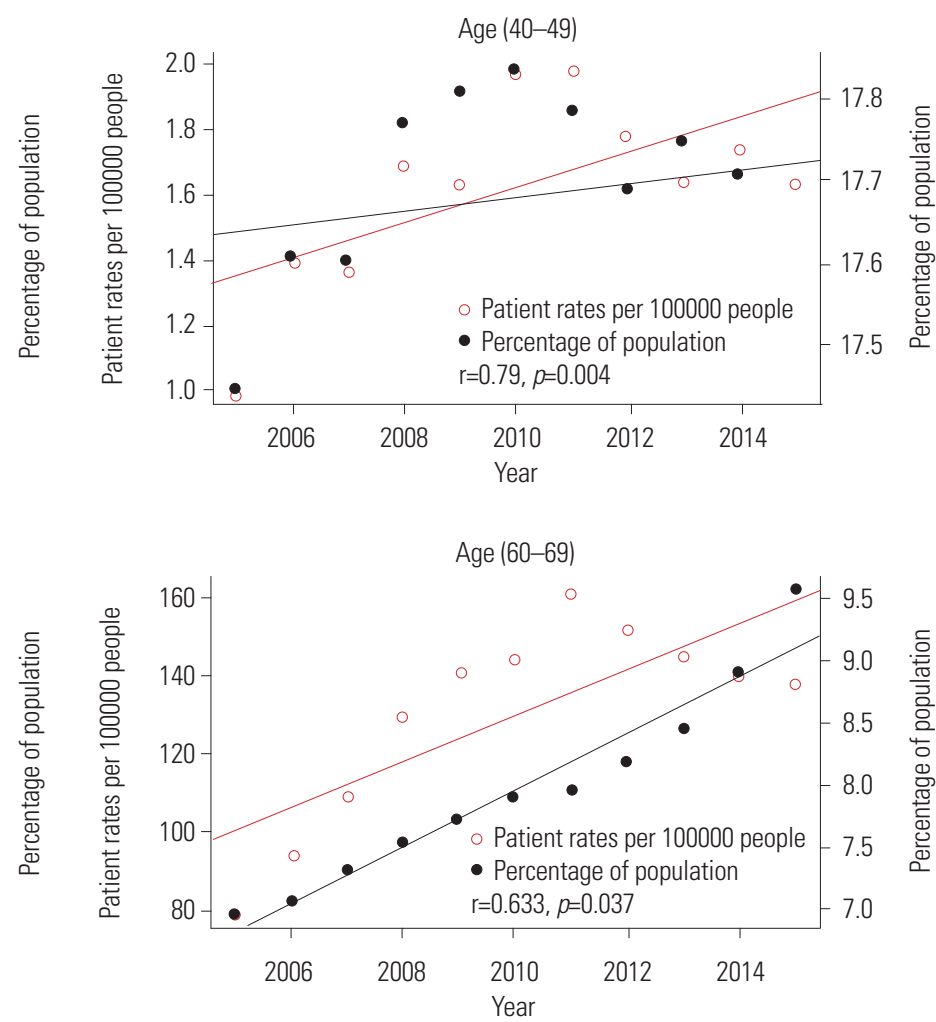

Fig. 4. Correlation between patient rates and percentage of population per year by age group.

complications, including urinary incontinence and erectile dysfunction, occurred less in the radiation therapy group than in the surgical treatment group both in the short and long term. ${ }^{27}$ Considering the relatively long survival of Pca patients after treatment of Pca and the quality of life in Pca patients, fewer complications are crucial. When new Pca patients decide the type of treatment, they might choose one that has less peri-operative and post-operative complications. ${ }^{28,29}$

Pca patients tend to decide to undergo other treatment options, including radiation therapy and active surveillance due to their similar oncologic results, with less or no risk, because morbidity increases with complications of general anesthesia or a huge operation. ${ }^{30}$ Hamdy, et al. ${ }^{31}$ reported that the metastasis and progression rates of Pca are higher in active surveillance groups than in RP and radiotherapy groups, although mortality rates are not significantly different among these groups. Wilt, et al. ${ }^{30}$ also reported that there is no significant difference in all-cause or Pca mortality between surgical treatment and active surveillance groups of localized Pca patients with over 10 years of follow up; meanwhile, surgical treatment elicited higher adverse events than active surveillance. ${ }^{30,31}$ Nevertheless, active surveillance is rarely used in South Korea, because the portion of localized Pca is $54 \%$, compared to $82 \%$ in the US. ${ }^{29}$ Pathological results for half of Pca patients who were treated by surgical treatment showed aggravated features, compared to prostate biopsy pathology results in South Korea. ${ }^{32}$ Surgical treatment including RP comprised a higher portion (60\%) of total Pca treatment in South Korea from 2000 to 2010 than (35\%) in the US from 2004 to $2013 .{ }^{12,13}$

In our study, Pca prevalence and surgical treatment including RP showed a decreasing trend due to age structural change, because South Korea has become an aging society. Based on 

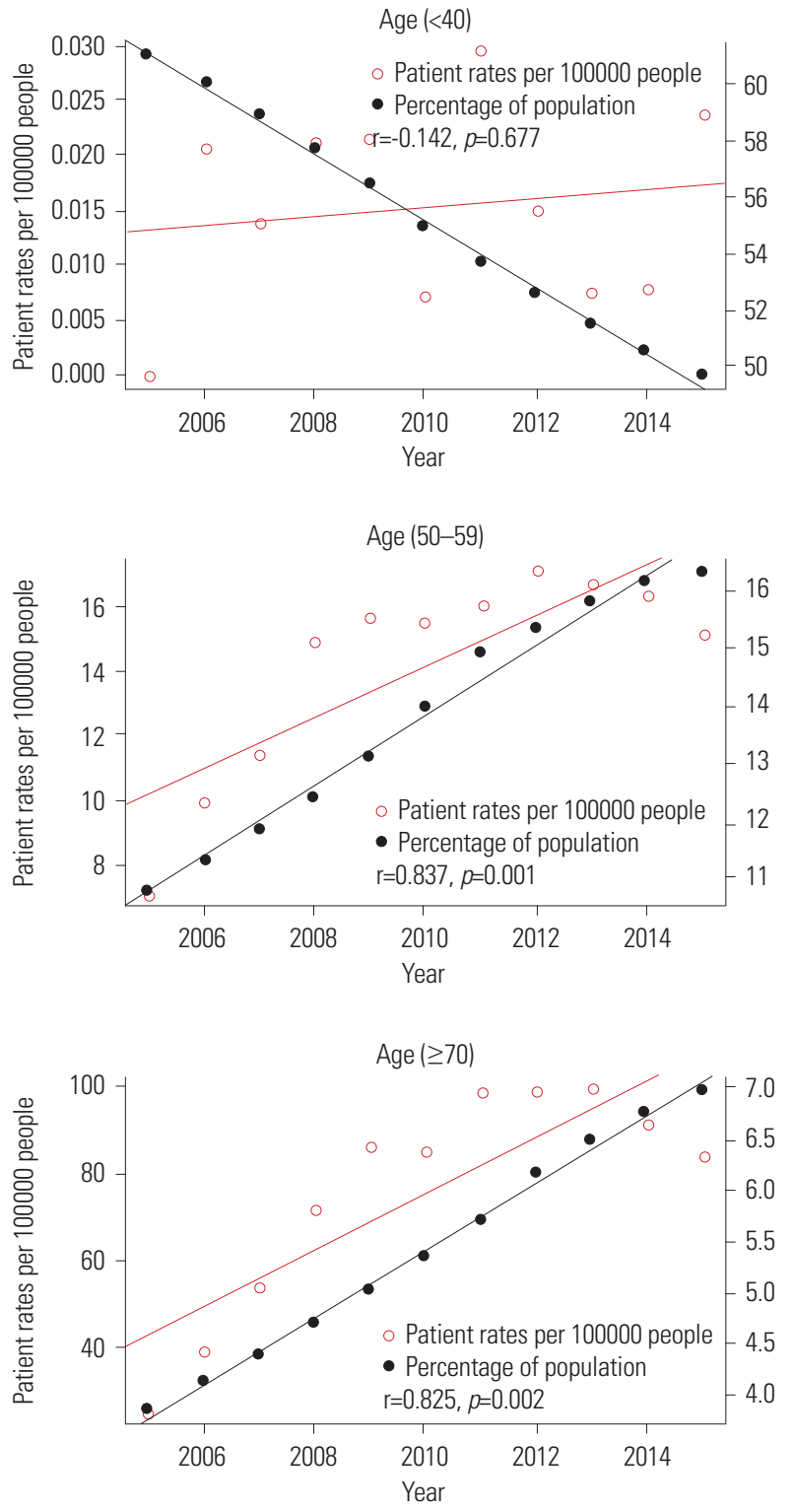
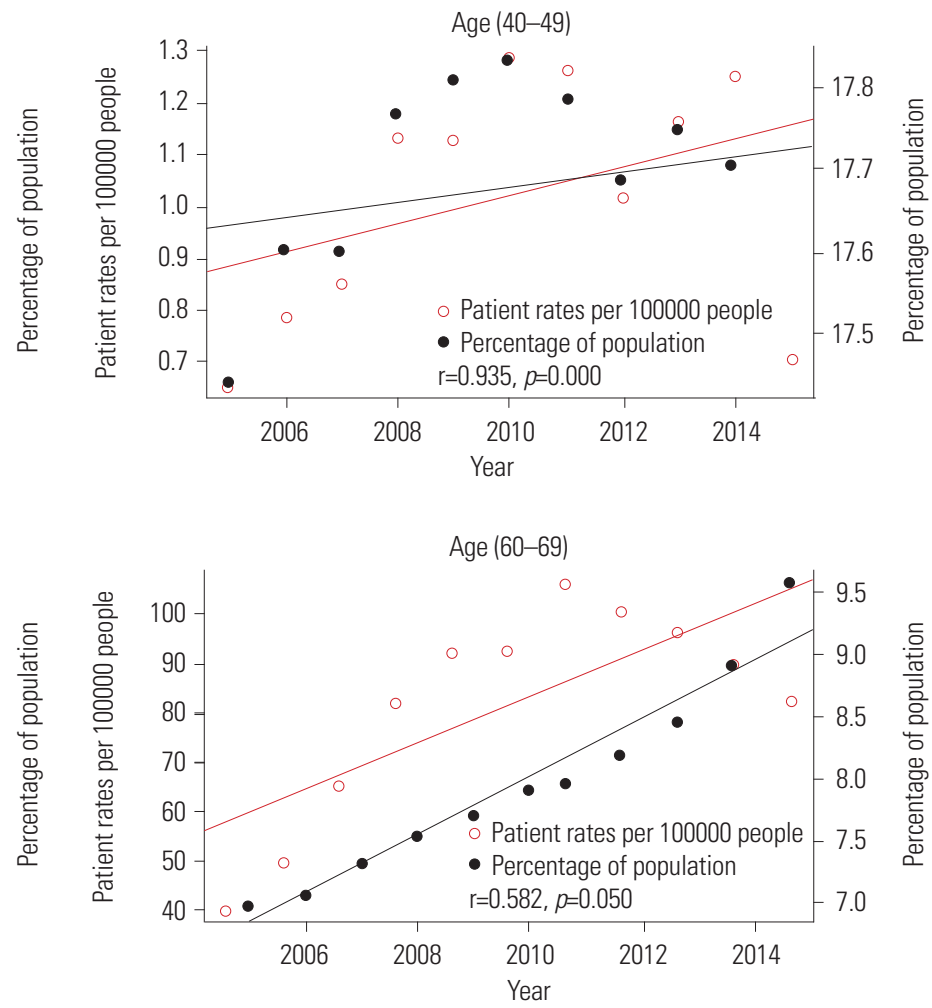

Fig. 5. Correlation between operation rates and percentage of population per year by age group.

our study results, we need guidelines for Pca screening and treatment considering South Korea has the fastest age structural change speed among OECD countries. More advanced studies are needed to verify our results.

Androgen deprivation therapy (ADT) was first introduced for Pca treatment in 1942. ADT can be used as an adjuvant therapy or combine therapy for advanced Pca. Even if it has no benefit for localized Pca, it can improve cancer-free survival and overall survival in advanced Pca. Considering this advantage of ADT, it should be used more for high-risk patients in the future. ${ }^{33}$

This study has several limitations. First, there was no statistical indicator of Pca incidence. Therefore, we could not differentiate patients who were newly diagnosed and those who were previously diagnosed. However, prevalence is more important than incidence itself because prevalence can reflect the real medical utilization rate and predict socioeconomic burden of Pca treatment and post-treatment. Second, there was no statistical information on other treatment options, including watchful waiting, active surveillance, radiation therapy, or hormone therapy. Our study was based on NHIS data that had no definite information on other treatments. The most difficult point that could be raised with using National Health Claim Data was that we could not define cases undergoing robotic surgeries. However, unlike other cancers, there is a validated method for identifying cases for robotic-assisted laparoscopic surgery for Pca. ${ }^{18}$ In South Korea, national health insurance covers Pca treatments, except stereotactic body radiation and robotic surgery. It covered $22.4 \%$ of all cancer patients in 2011; private insurance covered Pca treatments, including stereotactic body radiation and robotic surgery. ${ }^{34}$ Our previous study reported that radiation therapy for Pca, including stereotactic body radiation, had continuously increased 

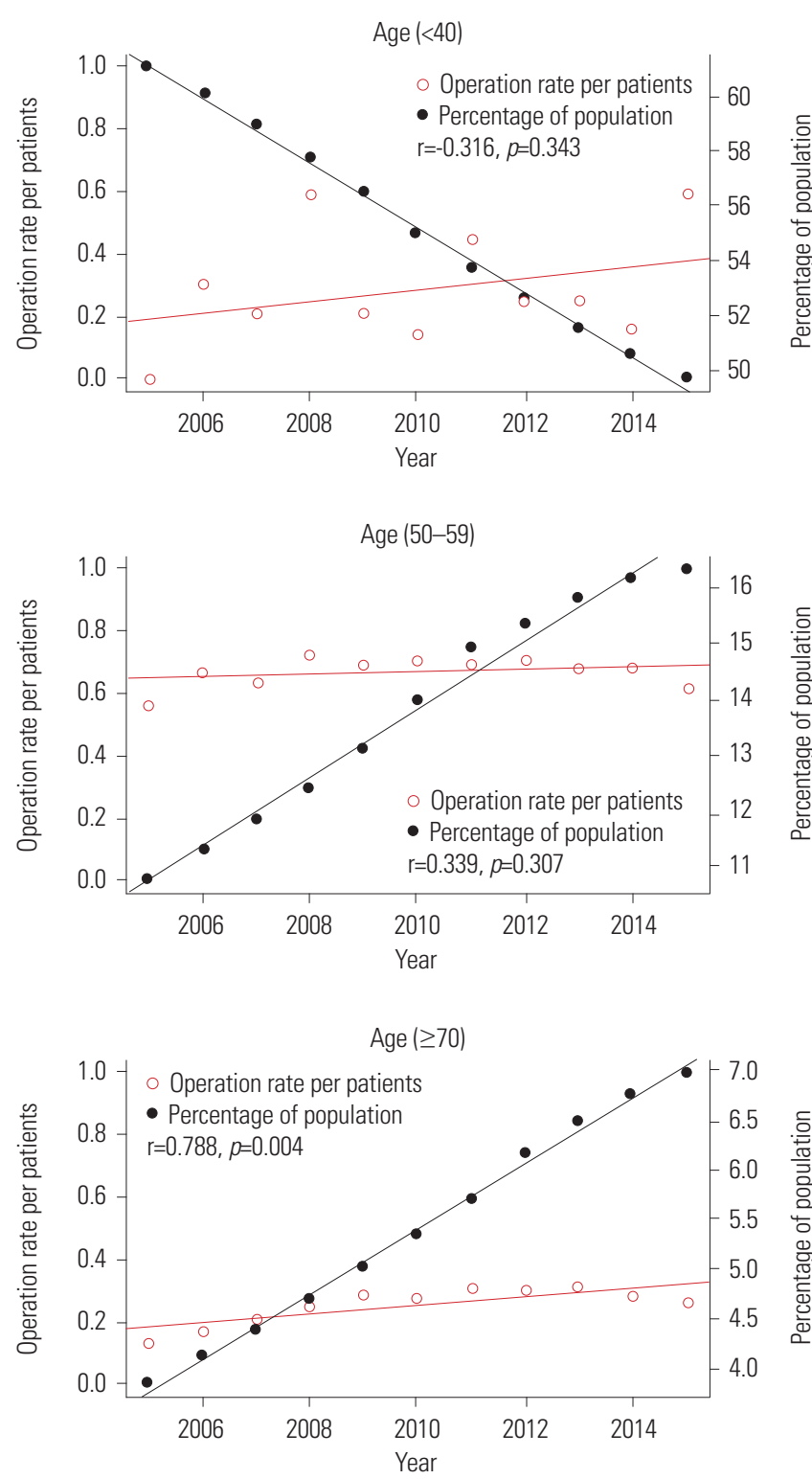

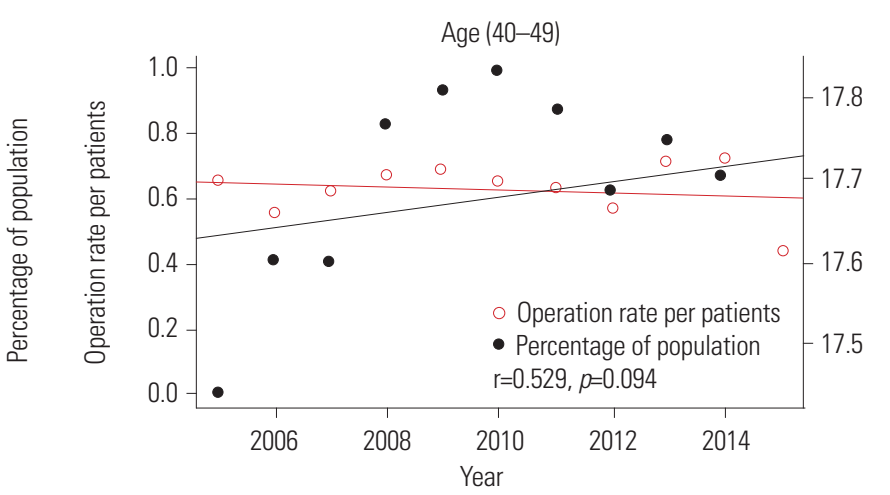

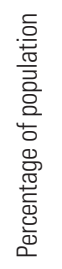
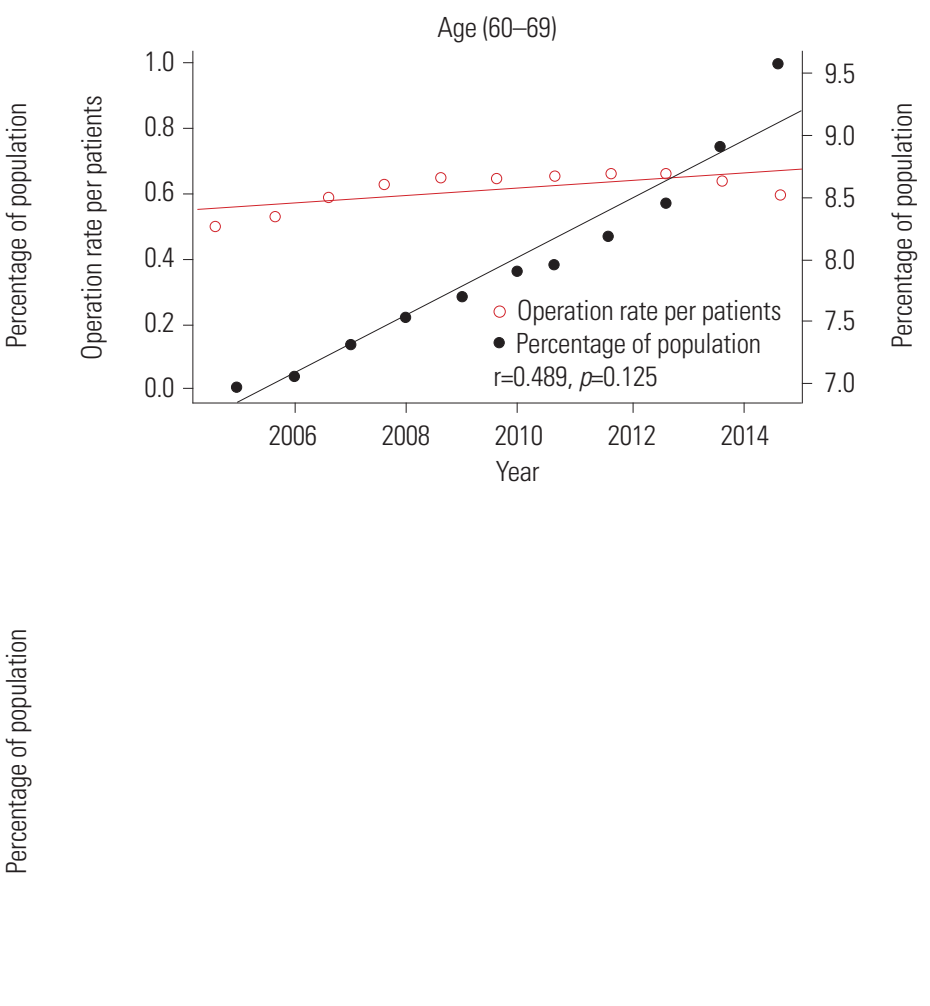

Fig. 6. Correlation between operation rates/patients and percentage of population per year by age group.

from 2005 to 2014. Considering these two factors, economic burden did not affect the choice of Pca treatment. ${ }^{35}$

This study revealed age structural change to be a unique feature of South Korea that could affect trends in the prevalence and surgical treatment rate of Pca, both of which were predicted to follow a decreasing trend according to age structural change. Future studies are needed to investigate underlying causes of the decreasing prevalence of Pca and surgical treatment rates for Pca. Possible socioeconomic and cultural factors affecting patient preferences for specific treatment options also need to be determined in the future.

\section{ACKNOWLEDGEMENTS}

This work was supported by the Soonchunhyang University Research Fund.

\section{AUTHOR CONTRIBUTIONS}

Conceptualization: Jae Heon Kim. Data curation: Hyun Young Lee, Suyeon Park. Formal analysis: Suyeon Park. Funding acquisition: Jae Heon Kim. Methodology: Jae Heon Kim. Supervision: Won Jae Yang, Yun Seob Song. Writing_original draft: Hyun Young Lee, Jae Heon Kim. Writing—review \& editing: All authors.

\section{ORCID iDs}

Hyun Young Lee Suyeon Park Seung Whan Doo Won Jae Yang Yun Seob Song Jae Heon Kim https://orcid.org/0000-0002-6706-3554 https://orcid.org/0000-0002-6391-557X https://orcid.org/0000-0002-5924-6908 https://orcid.org/0000-0002-7356-4312 https://orcid.org/0000-0002-0909-3341 https://orcid.org/0000-0002-4490-3610 


\section{REFERENCES}

1. Center MM, Jemal A, Lortet-Tieulent J, Ward E, Ferlay J, Brawley $\mathrm{O}$, et al. International variation in prostate cancer incidence and mortality rates. Eur Urol 2012;61:1079-92.

2. Song W, Jeon HG. Incidence of kidney, bladder, and prostate cancers in Korea: an update. Korean J Urol 2015;56:422-8.

3. Park SK, Sakoda LC, Kang D, Chokkalingam AP, Lee E, Shin HR, et al. Rising prostate cancer rates in South Korea. Prostate 2006;66: 1285-91.

4. Lim D, Ha M, Song I. Trends in major cancer mortality in Korea, 1983-2012, with a joinpoint analysis. Cancer Epidemiol 2015;39: 939-46.

5. Sammon JD, Abdollah F, D'Amico A, Gettman M, Haese A, Suardi $\mathrm{N}$, et al. Predicting life expectancy in men diagnosed with prostate cancer. Eur Urol 2015;68:756-65.

6. Kitazawa T, Matsumoto K, Fujita S, Seto K, Hanaoka S, Hasegawa T. Cost of illness of the prostate cancer in Japan--a time-trend analysis and future projections. BMC Health Serv Res 2015;15:453.

7. Roehrborn CG, Black LK. The economic burden of prostate cancer. BJU Int 2011;108:806-13.

8. Mistry PK, Gaunay GS, Hoenig DM. Prediction of surgical complications in the elderly: can we improve outcomes? Asian J Urol 2017;4:44-9.

9. Barocas DA, Alvarez J, Resnick MJ, Koyama T, Hoffman KE, Tyson $\mathrm{MD}$, et al. Association between radiation therapy, surgery, or observation for localized prostate cancer and patient-reported outcomes after 3 years. JAMA 2017;317:1126-40.

10. Daniyal M, Siddiqui ZA, Akram M, Asif HM, Sultana S, Khan A. Epidemiology, etiology, diagnosis and treatment of prostate cancer. Asian Pac J Cancer Prev 2014;15:9575-8.

11. Ahlering T, Huynh LM, Kaler KS, Williams S, Osann K, Joseph J, et al. Unintended consequences of decreased PSA-based prostate cancer screening. World J Urol 2018 Jul 12 [Epub]. Available at: https://doi.org/10.1007/s00345-018-2407-3.

12. Chen J, Oromendia C, Halpern JA, Ballman KV. National trends in management of localized prostate cancer: a population based analysis 2004-2013. Prostate 2018;78:512-20.

13. Ahn H, Kim HJ, Jeon SS, Kwak C, Sung GT, Kwon TG, et al. Establishment of Korean prostate cancer database by the Korean Urological Oncology Society. Investig Clin Urol 2017;58:434-9.

14. The Korean Urological Association, The Korean Urologocal Oncology Society. Korean clinical practice guideline for the treatment of prostate cancer [accessed on 2018 September 30]. Available at: http://www.urology.or.kr/mail/file/180912_2.pdf.

15. Lee EY, Kim HC, Rhee Y, Youm Y, Kim KM, Lee JM, et al. The Korean urban rural elderly cohort study: study design and protocol. BMC Geriatr 2014;14:33.

16. OECD. The percentage of elderly population in South Korea [accessed on 2019 January 1]. Avilable at: https://data.oecd.org/ pop/elderly-population.htm.

17. Baek MJ, Park S, Kim KH, Kim YH, Kim WK, Sun HY, et al. National trend of uroflowmetry, urodynamic study and cystoscopy considering the change in the population structure in Korea from 2010 to 2015. J Korean Med Sci 2018;33:e145.

18. Park J, Suh B, Shin DW, Hong JH, Ahn H. Changing patterns of primary treatment in Korean men with prostate cancer over 10 years: a nationwide population based study. Cancer Res Treat 2016;48:899-906.

19. Ahn HS. Overdiagnosis in health care: impact of cancer screening. J Korean Med Assoc 2017;60:323-9.

20. Townsend NT, Robinson TN. Surgical risk and comorbidity in older urologic patients. Clin Geriatr Med 2015;31:591-601.

21. Hall MJ, DeFrances CJ, Williams SN, Golosinskiy A, Schwartzman A. National hospital discharge survey: 2007 summary. National Health Statistics Reports; no 29. Hyattsville (MD): National Center for Health Statistics; 2010.

22. Kweon SS. Updates on cancer epidemiology in Korea, 2018. Chonnam Med J 2018;54:90-100.

23. Kim JH, Kim SY, Yun SJ, Chung JI, Choi H, Yu HS, et al. Medical travel among non-Seoul residents to seek prostate cancer treatment in medical facilities of Seoul. Cancer Res Treat 2019;51:53-64.

24. Hoffman RM, Meisner AL, Arap W, Barry M, Shah SK, Zeliadt SB, et al. Trends in United States prostate cancer incidence rates by age and stage, 1995-2012. Cancer Epidemiol Biomarkers Prev 2016;25: 259-63.

25. Mathieson KM, Kronenfeld JJ, Keith VM. Maintaining functional independence in elderly adults: the roles of health status and financial resources in predicting home modifications and use of mobility equipment. Gerontologist 2002;42:24-31.

26. Wolff RF, Ryder S, Bossi A, Briganti A, Crook J, Henry A, et al. A systematic review of randomised controlled trials of radiotherapy for localised prostate cancer. Eur J Cancer 2015;51:2345-67.

27. Tamada S, Ninomiya N, Kitamoto K, Kato M, Yamasaki T, Iguchi T, et al. Comparative effectiveness of radical prostatectomy and curative radiotherapy in localized prostate cancer: long-term followup. J Radiat Res 2017;58:552-8.

28. Donovan JL, Hamdy FC, Lane JA, Mason M, Metcalfe C, Walsh E, et al. Patient-reported outcomes after monitoring, surgery, or radiotherapy for prostate cancer. N Engl J Med 2016;375:1425-37.

29. Resnick MJ, Koyama T, Fan KH, Albertsen PC, Goodman M, Hamilton AS, et al. Long-term functional outcomes after treatment for localized prostate cancer. N Engl J Med 2013;368:436-45.

30. Wilt TJ, Jones KM, Barry MJ, Andriole GL, Culkin D, Wheeler T, et al. Follow-up of prostatectomy versus observation for early prostate cancer. N Engl J Med 2017;377:132-42.

31. Hamdy FC, Donovan JL, Lane JA, Mason M, Metcalfe C, Holding $\mathrm{C}$, et al. 10-year outcomes after monitoring, surgery, or radiotherapy for localized prostate cancer. N Engl J Med 2016;375:1415-24.

32. Hwang I, Lim D, Jeong YB, Park SC, Noh JH, Kwon DD, et al. Upgrading and upstaging of low-risk prostate cancer among Korean patients: a multicenter study. Asian J Androl 2015;17:811-4.

33. Park JW, Jang WS, Koh DH, Ham WS, Rha KH, Hong SJ, et al. Impact of early salvage androgen deprivation therapy in localized prostate cancer after radical prostatectomy: a propensity score matched analysis. Yonsei Med J 2018;59:580-7.

34. Yoo KB, Noh JW, Kwon YD, Cho KH, Choi Y, Kim JH. Having private cancer insurance in Korea: gender differences. Asian Pac J Cancer Prev 2015;16:7981-6.

35. Kim JH, Kim SY, Yun SJ, Chung JI, Choi H, Yu HS, et al. Medical travel among non-Seoul residents to seek prostate cancer treatment in medical facilities of Seoul. Cancer Res Treat 2019;51:53-64. 